\title{
Trigeminal Sensory Neuropathy in Mixed Connective Tissue Disease
}

Sharika Rajan ${ }^{1}$, Rajesh Gupta ${ }^{1}$, Maria J Borja², Naina Rastalksy ${ }^{3}$, Nagagopal Venna ${ }^{1}$ and Dinesh G Nair ${ }^{{ }^{*}}$

${ }^{1}$ Department of Neurology, Massachusetts General Hospital, USA

${ }^{2}$ Department of Radiology, Massachusetts General Hospital, USA

${ }^{3}$ Department of Rheumatology, Massachusetts General Hospital, USA

*Corresponding author: Dinesh G Nair, Department of Neurology, Massachusetts General Hospital, 15 Parkman St., Boston MA 02114-3117, USA, Tel: 617-726-3642; Fax: 617-726-2019; E-mail: dnair@mgh.harvard.edu

Received date: October 03, 2016; Accepted date: October 04, 2016; Published date: October 07, 2016

Copyright: (C) 2016 Rajan S, et al. This is an open-access article distributed under the terms of the Creative Commons Attribution License, which permits unrestricted use, distribution, and reproduction in any medium, provided the original author and source are credited.

\begin{abstract}
A 23 year old woman presented to the clinic with Raynaud's phenomenon and numbness and tingling in her right cheek, chin and the right side of her tongue. Examination showed altered facial sensation to touch and pinprick in the right V1-V3 distributions. When investigations revealed that her ANA was 1:5120 in a speckled pattern and antiRNP was $243.79 \mathrm{U}$, a diagnosis of Mixed Connective Tissue Disease (MCTD) was made. MRI brain showed diffuse enhancement of the Trigeminal nerves bilaterally, right>left. Trigeminal sensory neuropathy is the most common CNS manifestation of MCTD and often the presenting symptom. Prognosis is variable, some features respond to glucocorticoids.
\end{abstract}

Keywords: Raynaud's phenomenon; Trigeminal sensory neuropathy; Mixed connective tissue disease

\section{Image Description}

A 23 year old previously healthy woman presented to the clinic with initial symptoms suggestive of Raynaud's phenomenon (Figure 1), followed a few weeks later by bitemporal headaches and numbness and tingling on her right cheek, chin and the right side of her tongue. She also complained of fatigue and itching all over her body. She had no rash, oral ulcers, joint pain, swelling or hearing loss.

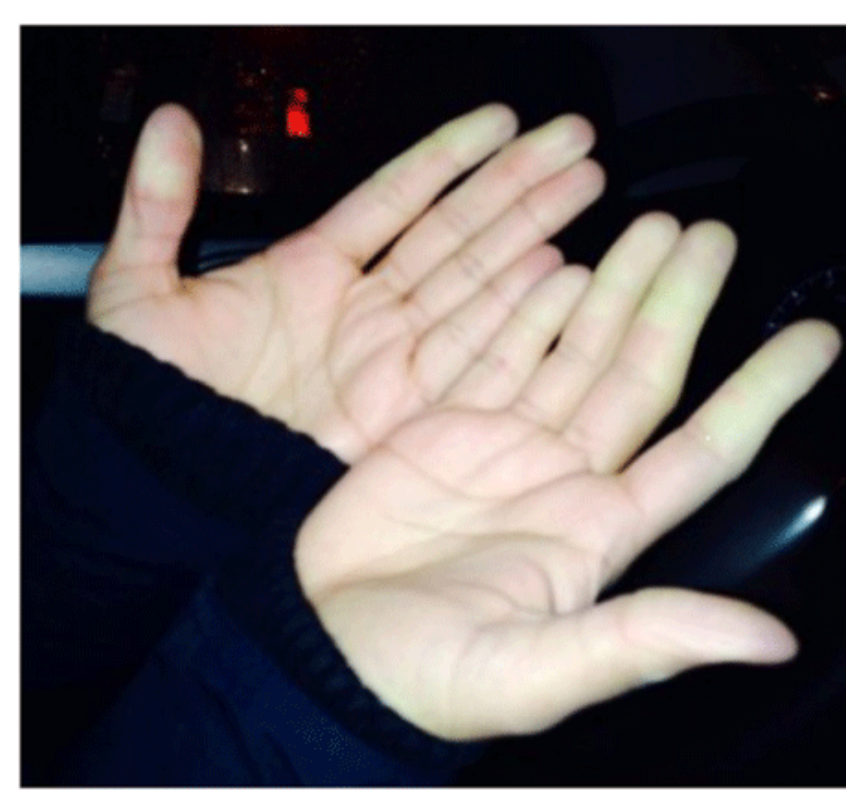

Figure 1: Raynaud's phenomenon.
On examination, facial sensation was altered to touch and pinprick in the right V1-V3 distributions. When investigations revealed that her ANA was 1:5120 in a speckled pattern, anti- RNP was 243.79 U, with negative anti- Ro/La, Sm, dsDNA and SCL-70, a clinical diagnosis of Mixed Connective Tissue Disease (MCTD) was made. MRI brain is shown below (Figure 2). Compared to the pre-contrast T1-weighted image (Figure 2A), diffuse enhancement of the Trigeminal nerves (short white arrows) is seen bilaterally, right $>$ left, in the post-contrast images (Figures 2B and 2C).

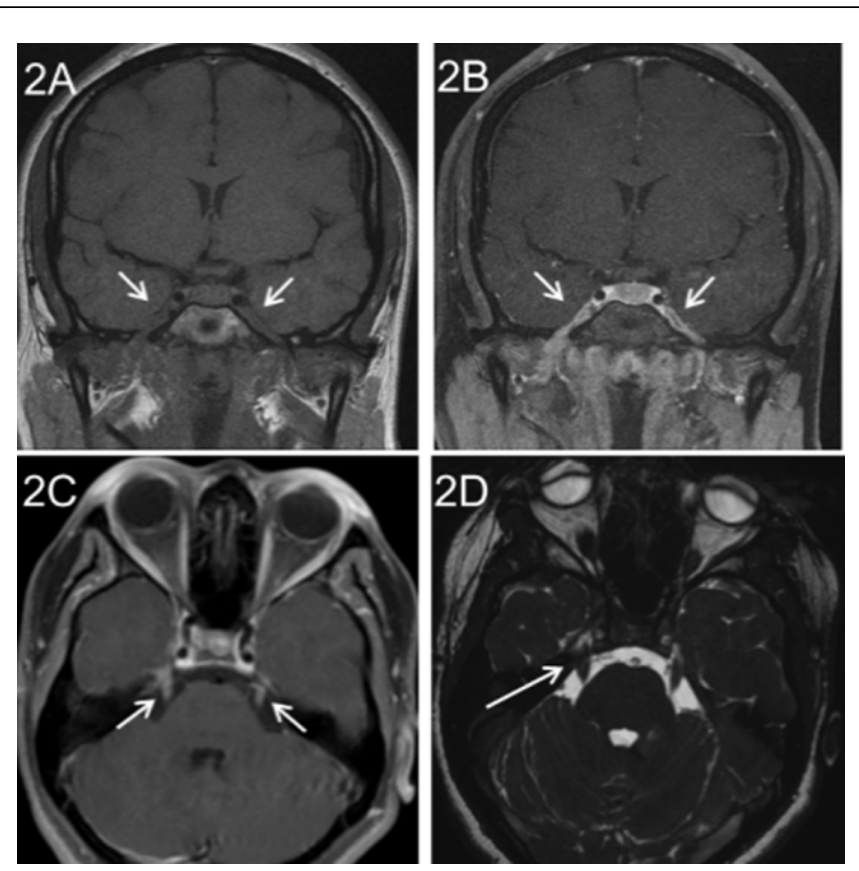

Figure 2: MRI brain. 
Citation: Rajan S, Gupta R, Borja MJ, Rastalksy N, Venna N, et al. (2016) Trigeminal Sensory Neuropathy in Mixed Connective Tissue Disease. J Neurol Neurophysiol 7: i106. doi:10.4172/2155-9562.1000i106

Page 2 of 2

Axial FIESTA sequence (Figure 2D) through the prepontine cistern and Meckel's cave demonstrates asymmetric prominence of the right Trigeminal nerve (long white arrow).

Trigeminal sensory neuropathy is the most common CNS manifestation of MCTD and often, the presenting symptom [1,2]. Prognosis is variable, some features respond to glucocorticoids. No therapy is effective for trigeminal neuropathy [3]; anti-epileptics and antidepressants may provide some relief. For our patient, treatment with Corticosteroids and Rituximab resolved her headache completely, but she continued to have mild facial numbness.

\section{References}

1. Edmondstone WM, Price DK, Shepherd TH, Gooddy WW (1982) Mixed connective tissue disease presenting as trigeminal neuropathy. Postgrad Med J 58: 237-238.

2. Hojaili B, Barland P (2006) Trigeminal neuralgia as the first manifestation of mixed connective tissue disorder. J Clin Rheumatol 12: 145-147.

3. Kim P, Grossman JM (2005) Treatment of mixed connective tissue disease. Rheum Dis Clin North Am 31: 549-565. 